\section{Ultraviolet-A Radiation Stimulates Growth of Indoor Cultivated Tomato (Solanum lycopersicum) Seedlings}

\author{
Soohyun Kang, Yating Zhang, Yuqi Zhang, Jie Zou, Qichang Yang,
} and $\mathrm{Tao}_{\mathrm{Li}}{ }^{\mathbf{1}}$

Institute of Environment and Sustainable Development in Agriculture, Chinese Academy of Agriculture Sciences, Beijing, China; and Key Laboratory of Energy Conservation and Waste Management of Agricultural Structures, Ministry of Agriculture, Beijing, China

Additional index words. UV-A radiation, plant growth, photosynthesis, Solanum lycopersicum

\begin{abstract}
Ultraviolet-A (UV-A) is the main component of UV radiation in nature. However, its role on plant growth, to a large extent, remains unknown. In this study, tomato (Solanum lycopersicum 'Beijing Cherry Tomato') seedlings were cultivated in an controlled environment in which UV-A radiation was provided by UV-A fluorescent lamps $\left(\lambda_{\max }=369 \mathrm{~nm}\right)$ with a fluence rate of $2.28 \mathrm{~W} \cdot \mathrm{m}^{-2}$. The photoperiod of $\mathrm{UV}-\mathrm{A}$ radiation was $0,4,8$, and 16 hours, which corresponds to control, $\mathrm{UV}-\mathrm{A} 4, \mathrm{UV}-\mathrm{A8}$, and UV-A16 treatments, respectively. The photosynthetic photon flux density (PPFD) was $220 \mu \mathrm{mol} \cdot \mathrm{m}^{-2} \cdot \mathrm{s}^{-1}$, which was provided by light-emitting diodes (LEDs) with a blue/red light ratio of 1:9, the photoperiod of $P P F D$ was 16 hours. We showed that supplementing 8 and 16 hours of $U V-A$ to visible radiation $(400-700 \mathrm{~nm})$ stimulated plant biomass production by $29 \%$ and $33 \%$, respectively, compared with that of control. This resulted mainly from larger leaves (i.e., $22 \%$ and $31 \%$ in 8 and 16 hours $\mathrm{UV}$-A, respectively), which facilitated light capture. Supplemental UV-A also enhanced photosynthetic capacity, as indicated by greater net photosynthesis rates in response to $\mathrm{CO}_{2}$ under saturating PPFD. Furthermore, the greatest stomatal conductance $\left(g_{\mathrm{S}}\right)$ value was observed in UV-A16, followed by UV-A8, which correlated with the greater stomatal density in the corresponding treatments. Moreover, supplemental UV-A did not induce any stress, as the maximum quantum efficiency of photosynthetic system II (PSII) $\left(F_{\mathrm{v}} / F_{\mathrm{m}}\right)$ remained $\approx 0.82$ in all treatments. Similarly, chlorophyll content and leaf mass area (LMA) were also unaffected by UV-A radiation. Taken together, we conclude that supplementing reasonable levels of UV-A to visible radiation stimulates growth of indoor cultivated tomato seedlings.
\end{abstract}

Plant growth and development are largely affected by spectra properties of light through mediating photosynthesis and photomorphogenesis. UV radiation critically influences terrestrial plants, and many studies are now available concerning the effect of UV-B (280-315 nm) on plant growth (HuchéThélier et al., 2016; Liu et al., 2011; Wargent et al., 2009). In nature, plants grow under sunlight where UV-A $(315-400 \mathrm{~nm})$ photons are present 10 to 100 times more than UV-B (Moan, 2002). Compared with UV-B, however, the number of studies on the effects of UV-A is very limited mainly as a result of a experimental design that often does not allow one to study the effect of UV-A independent from the effect of UV-B (Neugart and Schreiner, 2018; Verdaguer et al., 2017). Recently, the fast development of plant factories with artificial light (mainly LED)

Received for publication 29 June 2018. Accepted for publication 30 July 2018 .

This work was supported by the National Key Research and Development Program of China (no. 2017YFB0403900) and the Young Elite Scientists Sponsorship Program by CAST (2016QNRC001). 1'Corresponding author. E-mail: litao06@caas.cn. has led to the possibility that plants are cultivated in varying light spectra. However, the vast majority of research with lighting in plant factories has been conducted with only blue and red light (Hernández and Kubota, 2016; Trouwborst et al., 2016). As a consequence, it is still unknown whether additional UV-A radiation would benefit indoor plant cultivation.

Plants adjust their morphologic and physiologic processes in response to changing light conditions, which may stimulate or repress plant growth. A number of studies showed that UV-A radiation accelerated growth and modified the morphology of plants (Bernal et al., 2015; Tezuka et al., 1993). Conversely, some studies reported no significant responses or negative effects (i.e., inhibition of biomass accumulation and leaf expansion) under supplemental UV-A radiation (Krizek et al., 1997; Tsormpatsidis et al., 2008; Zhang et al., 2014). In this context, the direction of plant growth in response to UVA radiation is variable. Furthermore, available data do not allow the effect of the UV-A dose to be determined because of insufficient information on the fluence rates of the UV-A radiation used (Verdaguer et al., 2017).
Therefore, it is still unclear whether the growth of plants exhibits a dose response under UV-A radiation.

Photosynthesis is the ultimate basis for plant growth. The UV-A component of sunlight has been considered to be detrimental to photosynthesis (Kreslavski et al., 2013; Nayak et al., 2003). Under low (nonsaturating) light conditions, on the other hand, UVA can enhance photosynthesis rates. For instance, UV-A increased the photosynthesis rate by $8 \%$ to $10 \%$ in Poa annua, Sorghum halepense, and Nerium oleander under the background $P P F D$ of $500 \mu \mathrm{mol} \cdot \mathrm{m}^{-2} \cdot \mathrm{s}^{-1}$ (Mantha et al., 2001). In this aspect, supplemental UV-A radiation may improve carbon assimilation in indoor cultivation where the background $P P F D$ is often far less than the saturation intensity.

This study aims at exploring how plant growth responds to additional UV-A radiation in a controlled environment and whether plant growth exhibits a dose response under UV-A radiation. Tomato, the most widely cultivated vegetable in the world, was tested in this study. Plant morphologic and growth characteristics, and photosynthetic properties were studied.

\section{Materials and Methods}

Plant material and experimental setup. Tomato (Solanum lycopersicum 'Beijing Cherry Tomato'; Zhongshu seeds, CAAS, Beijing, China) seeds were germinated in rockwool plugs (Grodan, Roermond, the Netherlands) and transferred to rockwool cubes $(10 \times 10 \times 7 \mathrm{~cm}$; Grodan $)$ upon unfolding of the second leaf. Plants were grown in a growth chamber with a photoperiod (light/dark) of $16 / 8 \mathrm{~h}$ and ambient $\mathrm{CO}_{2}$ partial pressure. Light/dark temperature was $23 / 20{ }^{\circ} \mathrm{C}\left( \pm 1.5{ }^{\circ} \mathrm{C}\right)$ and average relative humidity was $65 \%$. Plants were irrigated regularly with modified Hoagland nutrient solution $(\mathrm{pH} \approx 5.5$; electrical conductivity $\approx$ $\left.1.8 \mathrm{dS} \cdot \mathrm{m}^{-1}\right)$. Two cultivation frames with two layers each were installed in the growth chamber, resulting in four individual cultivation cabinets $(70 \mathrm{~cm}$ wide $\times 150 \mathrm{~cm}$ long). Plants were subjected to $220 \mu \mathrm{mol} \cdot \mathrm{m}^{-2} \cdot \mathrm{s}^{-1}$ PPFD measured at plant level. PPFD was provided by a mixture of blue and red LED lamps (Dongguan Bio-lighting Sciences and Technology Co. Ltd, Dongguan, China) with a blue/red light ratio of 1:9. In each cultivation cabinet, a UV-A fluorescent lamp $(40 \mathrm{~W}$, $\lambda_{\max }=369 \mathrm{~nm}$ ) was installed in the middle of the LED lamps, and the regime of UV-A radiation was controlled individually. The fluence rate of UV-A radiation was 2.28 $\mathrm{W} \cdot \mathrm{m}^{-2}$ when measured at the same position as $P P F D$. Daily UV-A dose was weighed by using a biologic spectral weighing function according to Flint and Caldwell (2003). Detailed information about treatments is in Table 1 and the spectra distribution of PPFD and UV-A radiation are in Fig. 1. The greatest UV-A radiation level was $0.15 \mathrm{MJ} \cdot \mathrm{m}^{-2} \cdot \mathrm{d}^{-1}$ (i.e., UVA16 treatment), which was $\approx 31 \%$ of the average UV radiation in China $\left[0.49 \mathrm{MJ} \cdot \mathrm{m}^{-2} \cdot \mathrm{d}^{-1}\right.$ (Liu et al., 2017)]. Light-reflecting curtains 
Table 1. Lighting characteristics of the four ultraviolet-A treatments.

\begin{tabular}{lccc}
\hline Treatment & $\begin{array}{c}\text { Photoperiod of } \\
\text { ultraviolet-A (HR) }\end{array}$ & $\begin{array}{c}\text { Daily ultraviolet-A } \\
\text { dose }\left(\mathrm{kJ} \cdot \mathrm{m}^{-2} \cdot \mathrm{d}^{-1}\right)^{\mathrm{z}}\end{array}$ & $\begin{array}{c}\text { Daily PPFD } \\
\text { integral }\left(\mathrm{mol} \cdot \mathrm{m}^{-2}\right)\end{array}$ \\
\hline Control & - & - & 12.67 \\
Ultraviolet-A4 & $1200-1600$ & 0.58 & 12.67 \\
Ultraviolet-A8 & $1000-1800$ & 1.17 & 12.67 \\
Ultraviolet-A16 & $0600-2200$ & 2.34 & 12.67 \\
\hline
\end{tabular}

${ }_{\mathrm{z}}$ Daily ultraviolet-A dose was weighed by using a biologic spectral weighing function according to Flint and Caldwell (2003).

$P P F D=$ photosynthetic photon flux density (photon flux integral between 400 and $700 \mathrm{~nm}$, measured in micromoles per square meter per second).

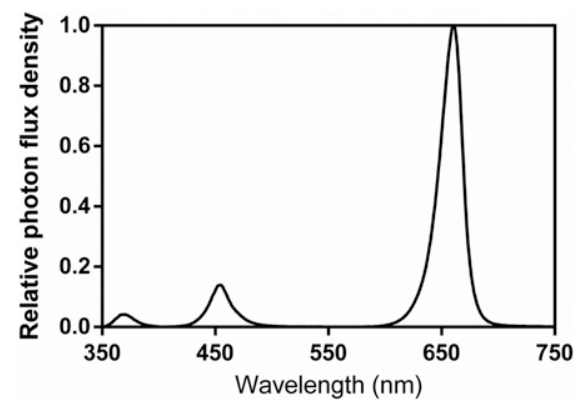

Fig. 1. Light spectra of the light environments in the growth cabinet measured at plant level.

were set up between each cabinet to prevent light disturbance from each other. Ten plants were grown in each treatment and they were rotated randomly on daily basis to guarantee homogeneous light distribution over the canopy. To get reliable information, plant cultivation was repeated four times and the treatment position was switched randomly whenever new cultivation started.

Plant growth analysis. Plants were destructively measured in the third week after transplanting, the measurements were taken in each round plant cultivation (i.e., four destructive measurements were taken in total). For each measurement, four to five plants per treatment were selected randomly. The fresh weight of leaves and stems was determined. They were dried for $48 \mathrm{~h}$ at $80^{\circ} \mathrm{C}$ in a ventilated oven. Leaf area was measured with a leaf area meter (Yaxin-1241; Yaxin Science, Beijing, China). Plant height was determined based on the stem length. LMA was calculated by dividing the leaf dry weight by leaf area of the leaf blades of the third leaf counted from the bottom.

Gas exchange and chlorophyll fluorescence. Measurements of gas exchange and chlorophyll fluorescence were performed using the LI-6400XT photosynthesis system (LI-COR Biosciences, Lincoln, NE) equipped with a leaf chamber fluorometer (LI-COR part no. 6400-40; area, $2 \mathrm{~cm}^{2}$ ). Three weeks after transplanting, the fourth leaf from the bottom of the plants was selected for measurement from four randomly selected plants. During the measurements, the $\mathrm{CO}_{2}$ partial pressure was $400 \mu$ bar (except when measuring the photosynthesis $\mathrm{CO}_{2}$ response curve), the leaf temperature was $25^{\circ} \mathrm{C}$, the leaf-to-air vapor pressure deficit was 0.7 to $1.0 \mathrm{kPa}$, and the flow rate was $500 \mu \mathrm{mol} \cdot \mathrm{s}^{-1}$. PPFD was provided by a mixture of red $(90 \%)$ and blue (10\%) LEDs in the fluorometer.
For measuring leaf photosynthesis $\left(A_{n}\right)$ in response to $P P F D$, the leaves were first adapted to the cuvette at $1500 \mu \mathrm{mol} \cdot \mathrm{m}^{-2} \cdot \mathrm{s}^{-1}$ PPFD until $A_{n}$ and $g_{\mathrm{S}}$ became stable, and a measurement was recorded. Then, they were exposed to $1200,900,600,400,300$, 200, 100, 50, and $0 \mu \mathrm{mol} \cdot \mathrm{m}^{-2} \cdot \mathrm{s}^{-1} P P F D$. At each $P P F D$, measurements were taken when $A_{n}$ reached a steady state (after about 5-10 $\min )$. The data were fitted to the nonrectangular hyperbola model of Thornley (1976), which estimated the maximum photosynthesis rate at saturating light, the light-limited quantum yield for $\mathrm{CO}_{2}$ fixation, and the dark respiration.

For determination of $A_{n}$ in response to $\mathrm{CO}_{2}$, the leaves were acclimated to 1500 $\mu \mathrm{mol} \cdot \mathrm{m}^{-2} \cdot \mathrm{s}^{-1}$ PPFD and $400 \mu$ bar $\mathrm{CO}_{2}$, until $A_{n}$ and $g_{\mathrm{S}}$ were stable, and a measurement was recorded. Thereafter, leaves were exposed to a range of $\mathrm{CO}_{2}$ partial pressures: 300, 200, 150, 100, 50, 400, 600, 800, 1000, 1200 , and $1500 \mu \mathrm{bar}$. At each $\mathrm{CO}_{2}$ level, measurements were taken when $A_{n}$ reached a steady state (after about 3-5 min for each step). Data from $\mathrm{CO}_{2}$ response curves were corrected for leaks of $\mathrm{CO}_{2}$ into or out of the cuvette by using photosynthetically inactive leaves (Flexas et al., 2007). $A_{n}$ as a function of intercellular $\mathrm{CO}_{2}$ partial pressure $\left(C_{\mathrm{i}}\right)$ was fitted through the model of Sharkey et al. (2007), which estimated the maximum carboxylation rate of ribulose 1, 5-bisphosphate carboxylase/oxygenase, Rubisco; the maximum rate of photosynthetic electron transport, and triose phosphate use.

During gas exchange measurements, chlorophyll fluorescence parameters $\left(F_{\mathrm{m}}{ }^{\prime}\right.$, maximum fluorescence yield of a lightadapted leaf; $F_{\mathrm{s}}$, fluorescence under actinic light; and $F_{\mathrm{o}}{ }^{\prime}$, minimum fluorescence yield of a light-adapted leaf) were recorded simultaneously. Maximum and minimum fluorescence yield of dark-adapted leaves $\left(F_{\mathrm{m}}\right.$ and $F_{\text {or }}$, respectively) were measured with the leaves fully dark adapted for a whole night. Detailed settings for the fluorescence measurements followed those of Zhang et al. (2018). Based on these data, the quantum efficiency of PSII (ФPSII), and $F_{\mathrm{v}} / F_{\mathrm{m}}$ were estimated according to Baker (2008).

Stomatal conductance. Stomatal conductance was measured with a porometer (model AP4; Delta-T Devices, Cambridge, UK). Four plants were selected randomly from each treatment as four replicates. One leaflet of the fourth leaf from the bottom of the plant was selected, and the measurements were done in situ when UV-A lamps were turned on in all treatments (i.e., from 1300 to $1500 \mathrm{HR}$ ). Stomatal conductance was recorded in four different positions in each leaf blade, which were considered as four technical replicates, and the mean value of four technical replicates was considered as one biologic replicate.

Leaf optical properties. Leaf reflectance and transmittance were measured within the visible spectrum $(400-700 \mathrm{~nm})$ with a spectroradiometer (USB2000+; Ocean Optics, Largo, FL) in combination with two integrating spheres (FOIS-1 and ISP-REF, Ocean Optics). Leaf absorptance (Ab) was calculated as $A b=1-(R f+T r)$, where $R f$ and $T r$ are the reflectance and transmittance of leaf samples, respectively. Four leaflets from different plants were selected randomly for these measurements. In each leaflet, the measurements were taken in three different positions; they were considered as three technical replicates.

Chlorophyll content and stomatal density. At the fourth week after transplanting, four leaf disks $1.6 \mathrm{~cm}$ in diameter were punched out from four different plants to determine chlorophyll $a$ and $b$ contents. Acetone (80\%) was used as the solvent, and the absorbance of the extracts was measured using a UV/Vis spectrophotometer (model UV-1800; Shimadzu, Kyoto, Japan). The chlorophyll concentrations were calculated using the equations derived by Wellburn (1994). Stomatal density was determined according to Zhang et al. (2018).

Statistical analysis. The effects of UV-A on plant growth and physiologic traits were evaluated by analysis of variance followed by Fisher's protected least significant difference test at 95\% confidence with R 3.4.0 (R Foundation for Statistical Computing, Vienna, Austria). The four destructive measurements were considered as four blocks in statistical analysis. $P$ values less than 0.05 were regarded as significantly different.

\section{Results}

The growth of tomato seedlings showed a positive response to supplemental UV-A radiation (Fig. 2). Specifically, supplementing 8 and $16 \mathrm{~h}$ of UV-A to visible radiation stimulated plant biomass production by $29 \%$ and $33 \%$, respectively, compared with that of the control. Such a stimulating effect did not occur in the treatment of 4-h UV-A supplementation (Fig. 2A). A similar effect was observed for plant leaf area, which was $22 \%$ and $31 \%$ greater in the UV-A8 and UV-A16 treatments, respectively, compared with the control (Fig. 2B). Stem length was also stimulated by supplemental UV-A radiation, although the tallest plants were seen in the UV-A8 treatment (Fig. 2C).

The response of $A_{n}$ and $\Phi$ PSII to PPFD were unaffected by UV-A radiation (Fig. 3A and C; Table 2). However, supplemental UVA remarkably affected the response of $A_{n}$ and $\Phi P S I I$ to $C_{\mathrm{i}}$. Specifically, plants grown in the UV-A8 and UV-A16 treatments displayed greater $A_{n}$ and $\Phi$ PSII than the other treatments, particularly under greater $\mathrm{CO}_{2}$ concentrations (Fig. 3B and D), whereas plants in 


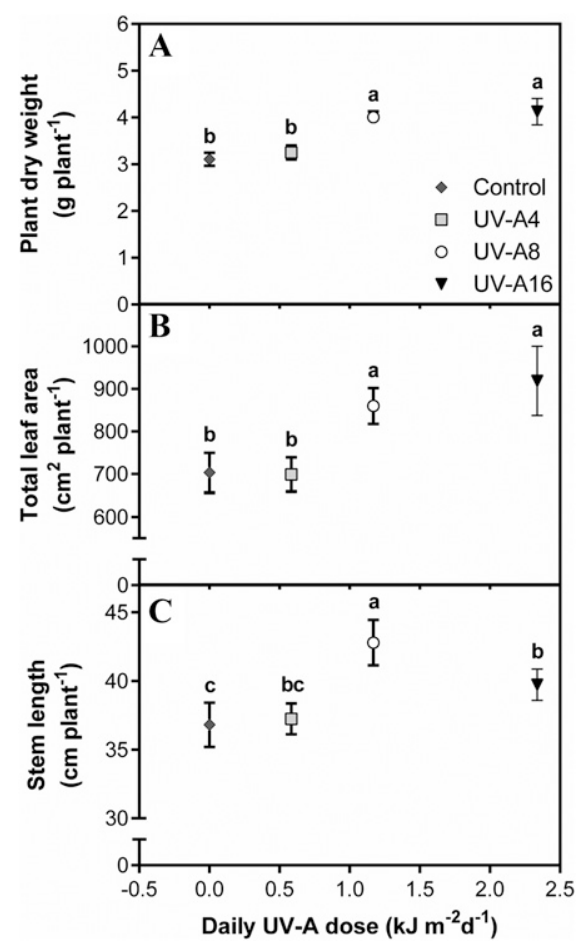

Fig. 2. The effect of different ultraviolet (UV)-A treatments on (A) plant dry weight, (B) leaf area, and (C) stem length. Different letters indicate statistically significant differences among treatments $(P<0.05)$. Error bars show \pm SE $(\mathrm{n}=17)$.

the UV-A4 treatment had a similar photosynthetic capacity as that of the control (Fig. 3B).

Plants grown under different UV-A doses showed substantial differences in $g_{\mathrm{S}}$ (Fig. 4), which was greatest in the UV-A16 treatment, followed by UV-A8, and it was similar between the treatment of UV-A4 and the control. Corresponding to $g_{\mathrm{S}}$, the effect of UV-A on stomatal density was also significant (Table 3 ). With regard to the abaxial side of the leaf, stomatal density in the UV-A8 and UV-A16 treatments was higher than the other treatments. With regard to the adaxial side, a significant difference was seen only between the UV-A8 and UV-A4 treatments, which showed the greatest and least values, respectively.

Leaf absorptance spectra of all treatments were similar in most parts of the visible waveband (400-700 nm), except in the green region $(530-580 \mathrm{~nm})$. In the green spectrum, leaves of the UV-A16 treatment had the greatest absorptance, followed by the UVA8 and UV-A4 treatments. Absorptance was least in the control (Fig. 5).

$F_{\mathrm{v}} / F_{\mathrm{m}}$ values were similar $(\approx 0.82)$ in all treatments (Table 3 ). Similarly, chlorophyll $a+b$ content, chlorophyll $a / b$ ratio, and LMA were also not affected significantly by supplemental UV-A (Table 3).

\section{Discussion}

Adding UV-A to visible radiation in a controlled environment accelerates the growth of tomato seedlings significantly, as showed by

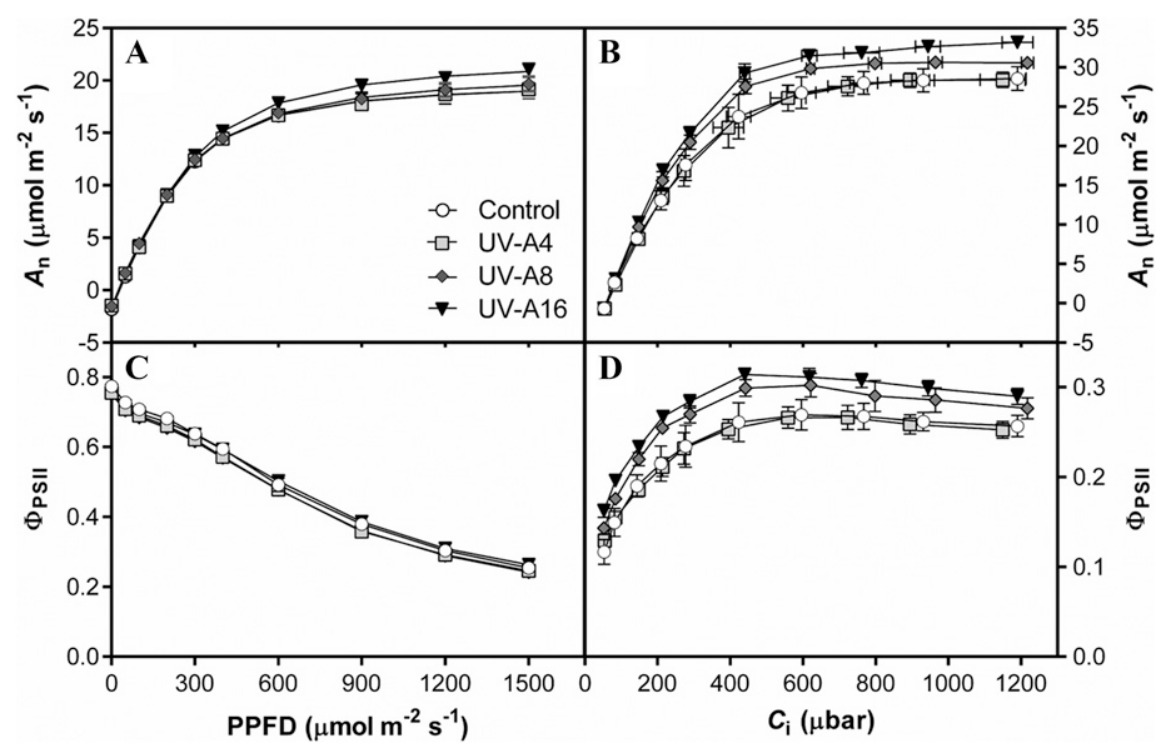

Fig. 3. The effect of different ultraviolet (UV)-A treatments on the response of photosynthesis rates $\left(A_{n}\right)$ to (A) photosynthetic photon flux density $(P P F D)$ and (B) intercellular $\mathrm{CO}_{2}$ partial pressures $\left(C_{\mathrm{i}}\right)$, as well as the quantum efficiency of photosynthetic system II (ФPSII) to (C) PPFD and (D) $C_{\mathrm{i}}$. Error bars show \pm SE $(\mathrm{n}=4)$.

Table 2. The effect of different ultraviolet-A treatments on photosynthetic parameters derived from the photosynthetic light and $\mathrm{CO}_{2}$ response curve fitting $(\mathrm{n}=4)$.

\begin{tabular}{lcccccc}
\hline Treatments & $\begin{array}{c}A_{\max } \\
\left(\mu \mathrm{mol} \cdot \mathrm{m}^{-2} \cdot \mathrm{s}^{-1}\right)\end{array}$ & $\left.\begin{array}{c}\alpha \\
\left(\mathrm{mol} \cdot \mathrm{mol}^{-1}\right)\end{array}\right)$ & $\begin{array}{c}\mathrm{R}_{\mathrm{D}} \\
\left(\mu \mathrm{mol} \cdot \mathrm{m}^{-2} \cdot \mathrm{s}^{-1}\right)\end{array}$ & $\begin{array}{c}V_{c, \max } \\
\left(\mu \mathrm{mol} \cdot \mathrm{m}^{-2} \cdot \mathrm{s}^{-1}\right)\end{array}$ & $\begin{array}{c}J_{\max } \\
\left(\mu \mathrm{mol} \cdot \mathrm{m}^{-2} \cdot \mathrm{s}^{-1}\right)\end{array}$ & $\begin{array}{c}\mathrm{TPU} \\
\left(\mu \mathrm{mol} \cdot \mathrm{m}^{-2} \cdot \mathrm{s}^{-1}\right)\end{array}$ \\
\hline Control & 21.92 & 0.06 & 1.81 & $76.25 \mathrm{ab}$ & $142.92 \mathrm{bc}$ & $10.35 \mathrm{bc}$ \\
Ultraviolet-A4 & 21.65 & 0.06 & 1.51 & $69.71 \mathrm{~b}$ & $133.63 \mathrm{c}$ & $9.77 \mathrm{c}$ \\
Ultraviolet-A8 & 22.68 & 0.07 & 1.56 & $80.80 \mathrm{a}$ & $150.06 \mathrm{ab}$ & $10.63 \mathrm{ab}$ \\
Ultraviolet-A16 & 24.21 & 0.06 & 1.70 & $86.24 \mathrm{a}$ & $160.14 \mathrm{a}$ & $11.34 \mathrm{a}$ \\
\hline
\end{tabular}

Means followed by different letters within one column differ significantly $(P<0.05)$ as established by the least significant difference test.

$A_{\max }=$ maximum photosynthesis rate; $\alpha=$ light-limited quantum yield for $\mathrm{CO}_{2}$ fixation; $\mathrm{R}_{\mathrm{D}}=$ dark respiration; $V_{c, \max }=$ maximum carboxylation rate of Rubisco; $J_{\max }=$ maximum electron transport rate; $\mathrm{TPU}=$ triose phosphate utilization rate.

the $29 \%$ to $33 \%$ enhancement in total plant biomass in our study (Fig. 2A), which is contrary to the effect of UV-B, which often represses plant growth (Tsormpatsidis et al., 2008). This is in consistent with previous studies carried out either in greenhouse or in open field conditions with cutoff filters or supplemental UV-A radiation (Bernal et al., 2015; Tezuka et al., 1993). However, some studies indicated that plant biomass was reduced by UV-A radiation (Baroniya et al., 2013; Krizek et al., 1998). Such a discrepancy in plant growth in response to UV-A radiation remains ambiguous because the information regarding the effect of UV-A on plant biomass production is limited. Verdaguer et al. (2017) proposed that the variable UV-A responses may be caused by small changes in the balance between multiple, simultaneous UV-A effects, including induced stress, changes in morphology and photosynthesis, as well as accumulation of phenolic compounds with antioxidative capabilities. Furthermore, it has been reported that some effects of UV-A on biomass accumulation are modulated by other environmental factors (Bernal et al., 2013). Nevertheless, this may not play a role in our study as all environmental factors were kept constant except irradiance.

Light interception correlates closely with the morphology of shoots, which is one of the

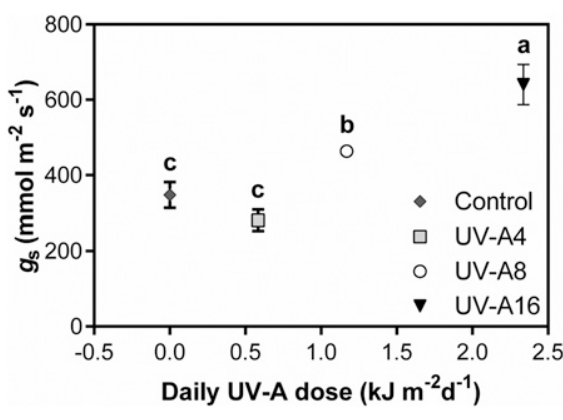

Fig. 4. The effect of different ultraviolet (UV)-A treatments on stomatal conductance $\left(g_{\mathrm{S}}\right)$. The measurements were taken during middle of the day when ultraviolet-A lamps were turned on in all treatments. Different letters indicate statistically significant differences among treatments $(P<0.05)$. Error bars show \pm SE $(n=4$, each replicate represents the mean of four different measurement positions in the same leaflet).

driving forces behind plant photosynthesis (Sarlikioti et al., 2011). Previous studies demonstrated that UV-A stimulates leaf elongation in beans (Antonelli et al., 1997). This is in line with our study in which supplementary UV-A radiation increased total leaf area by $22 \%$ to $31 \%$ (Fig. 2B). The larger leaves facilitated light capture and, consequently, 
Table 3. Physiologic and morphologic properties of leaves in response to different ultraviolet-A treatments $(n \geq 4)$.

\begin{tabular}{lcccccr}
\hline & Chlorophyll & & & & \multicolumn{2}{c}{$\mathrm{SD}\left(\mathrm{no} . \mathrm{mm}^{2}\right)$} \\
\cline { 5 - 7 } Treatments & $a+b\left(\mathrm{mg} \cdot \mathrm{m}^{-2}\right)$ & Chlorophyll $a / b$ & $F_{\mathrm{v}} / F_{\mathrm{m}}$ & LMA $\left(\mathrm{g} \cdot \mathrm{m}^{-2}\right)$ & Adaxial & Abaxial \\
\hline Control & 409.4 & 3.08 & 0.820 & 20.37 & $102.4 \mathrm{ab}$ & $235.8 \mathrm{~b}$ \\
Ultraviolet-A4 & 414.1 & 3.07 & 0.818 & 19.91 & $95.4 \mathrm{~b}$ & $236.7 \mathrm{~b}$ \\
Ultraviolet-A8 & 436.8 & 3.06 & 0.821 & 21.38 & $135.9 \mathrm{a}$ & $296.9 \mathrm{a}$ \\
Ultraviolet-A16 & 440.4 & 3.03 & 0.821 & 21.82 & $116.9 \mathrm{ab}$ & $289.9 \mathrm{a}$ \\
$P$ value & 0.128 & 0.743 & 0.382 & 0.225 & 0.045 & 0.001 \\
\hline
\end{tabular}

$\mathrm{F}_{\mathrm{v}} / \mathrm{F}_{\mathrm{m}}=$ maximum quantum efficiency of photosynthetic system II; LMA = leaf mass area; $\mathrm{SD}=$ stomatal density.

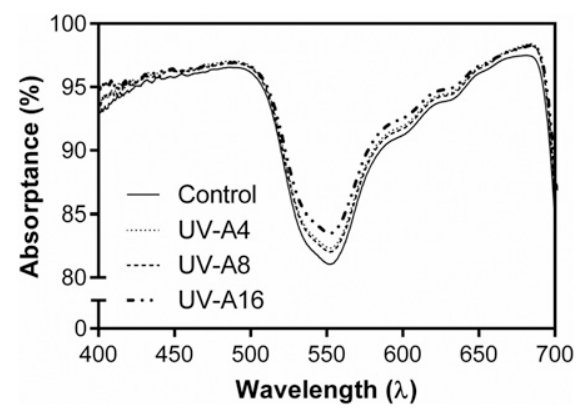

Fig. 5. The effect of different ultraviolet (UV)-A treatments on leaf absorptance within the range of the visible spectrum $(400-700 \mathrm{~nm} ; \mathrm{n}=4)$. The measurements were taken on four leaflets from four different plants, and three different positions were measured in each leaflet.

contributed to biomass production (Fig. 2A). Although detailed information about the way that UV-A radiation mediates leaf expansion is lacking, UV-A exposure may upregulate the expression of cryla (Mariz-Ponte et al., 2018), as cry-impaired plants have exhibited significantly smaller leaf blades (Kozuka et al., 2005). Thus, it is assumed that upregulation of cryptochrome by UV-A promotes leaf expansion (Mishra and Khurana, 2017). In addition to leaf size, plant height was also slightly increased by UV-A radiation (Fig. 2C), and a similar phenomenon has been noted in some Sorghum bicolor varieties (Kataria and Guruprasad, 2012). Such effects have been attributed to blue/UV-A absorbing cryptochromes, which can play a role in shade avoidance (Keller et al., 2011). However, there are also studies that reported that UV-A radiation decreased plant height (Dáder et al., 2014; Rechner et al., 2017). In this context, more evidence is needed to corroborate speculations about UV-A radiation playing a functional role in countering the shade-acclimated phenotype.

Plant growth processes often exhibit a saturation response to growth irradiance (Taiz and Zeiger, 2006). In the current study, although the UV-A radiation level in the UV-A8 treatment was half of that in the UV-A16 treatment, the total leaf area and biomass production in the UV-A8 treatment were similar, as in the UV-A16 treatment (Fig. 2), which indicates that plant growth may show a saturation response to UV-A radiation level. Moreover, compared with 8 and $16 \mathrm{~h}$ of supplemental UV-A, $4 \mathrm{~h}$ of supplemental UV-A hardly affected plant growth and leaf expansion (Fig. 2). This is probably results from the fact that $4 \mathrm{~h}$ of supplemental UV-A radiation was not enough to induce the stimulation of plant growth, as the UV-A radiation level in the UV-A4 treatment was only $\approx 8 \%$ of the average UV radiation in nature (Liu et al., 2017). Therefore, our results indicate that UV-A radiation may affect plant growth qualitatively, but detailed studies are needed to elucidate its mechanisms.

Plant photosynthesis is highly sensitive to its prevailing growth environment. Conventionally, the UV component of solar radiation has been considered to be detrimental to photosynthesis, as UV radiation induces the degradation of D1 and D2 proteins in the photosynthetic apparatus, and consequent destruction of PSII (Christopher and Mullet, 1994; Greenberg et al., 1989). However, the maximum quantum efficiency of PSII photochemistry was unaffected by UV-A radiation in our study, as reflected by the similar $F_{\mathrm{v}} / F_{\mathrm{m}}$ values $(\approx 0.82)$ among the treatments (Table 3), which indicates that plants were not stressed with a well-functioning photosynthetic apparatus. Furthermore, the net photosynthesis rate in response to $P P F D$ was also unaffected by UV-A (Fig. 3A), which correlates with the same response of ФPSII at different PPFD (Fig. 3C). This is not surprising because previous studies have shown that, under low light or nonsaturating background PPFD (e.g., $500 \mu \mathrm{mol} \cdot \mathrm{m}^{-2} \cdot \mathrm{s}^{-1}$ ), $\mathrm{UV}-\mathrm{A}$ radiation did not affect the functions of the photosynthetic apparatus and even enhanced photosynthetic rates (Mantha et al., 2001). This is further confirmed by the UVA-acclimated plants showing greater net photosynthesis rates in response to $\mathrm{CO}_{2}$ under saturating PPFD (Fig. 3B). Our results indicate that reasonable levels of UV-A increase the potential of photosynthetic capacity, but this might not attribute to the biomass accumulation as plants were grown under ambient $\mathrm{CO}_{2}$ and low PPFD in this study.

Light is one of the key stimuli for regulating stomatal traits. The significantly greater $g_{\mathrm{S}}$ in the UV-A8 and UV-A16 treatments correlated with the corresponding greater stomatal density (Fig. 4; Table 3). Furthermore, it has also been proposed that the greater $g_{\mathrm{S}}$ under UV-A radiation might be a result of increased stomatal opening, which is caused by the absorption of UV-induced blue/green fluorescence by cryptochromes located in stomata (Mantha et al., 2001). The greater $g_{\mathrm{S}}$ can decrease the diffusional limitation of $\mathrm{CO}_{2}$ into the leaf and facilitate carbon assimilation. Apart from $g_{\mathrm{S}}$, leaves grown under a greater supplemental UV-A dose showed an increased absorptance in the green region of the spectra (Fig. 5). It has been reported that anthocyanins absorb light in the green region of the spectra (Merzlyak et al., 2008), which was supported by the work of Gitelson et al. (2001) with maple leaves. Hence, plants grown under supplemental UV-A radiation probably have a greater anthocyanin concentration.

Although UV-A radiation is rarely applied in indoor cultivation systems compared with other light spectra, we have shown that allowing reasonable levels of UV-A radiation in a controlled environment boosts the growth of tomato seedlings. The results shown here may provide a direction for optimizing a light recipe for indoor cultivation.

\section{Conclusions}

We conclude that UV-A radiation stimulates growth of tomato seedlings in indoor cultivation, as indicated by greater biomass production, which resulted mainly from the larger expansion of leaf area that facilitated light capture. This stimulating effect exhibited a saturation response to the UV-A dose.

\section{Literature Cited}

Antonelli, F., D. Grifoni, F. Sabatini, and G. Zipoli. 1997. Morphological and physiological responses of bean plants to supplemental UV radiation in a Mediterranean climate. Plant Ecol. 128:127-136.

Baker, N.R. 2008. Chlorophyll fluorescence: A probe of photosynthesis in vivo. Annu. Rev. Plant Biol. 59:89-113.

Baroniya, S.S., S. Kataria, G.P. Pandey, and K.N. Guruprasad. 2013. Intraspecific variations in antioxidant defense responses and sensitivity of soybean varieties to ambient UV radiation. Acta Physiol. Plant. 35:1521-1530.

Bernal, M., L. Llorens, J. Badosa, and D. Verdaguer. 2013. Interactive effects of UV radiation and water availability on seedlings of six woody Mediterranean species. Physiol. Plant. 147:234 247.

Bernal, M., D. Verdaguer, J. Badosa, A. Abadía, J. Llusià, J. Peñuelas, E. Núñez-Olivera, and L. Llorens. 2015. Effects of enhanced UV radiation and water availability on performance, biomass production and photoprotective mechanisms of Laurus nobilis seedlings. Environ. Expt. Bot. 109:264-275.

Christopher, D.A. and J.E. Mullet. 1994. Separate photosensory pathways co-regulate blue light/ ultraviolet-A-activated psbD-psbC transcription and light-induced D2 and CP43 degradation in barley (Hordeum vulgare) chloroplasts. Plant Physiol. 104(4):1119-1129.

Dáder, B., D. Gwynn-Jones, A. Moreno, A. Winters, and A. Fereres. 2014. Impact of UV-A radiation on the performance of aphids and whiteflies and on the leaf chemistry of their host plants. J. Photochem. Photobiol. Bol. Biol. 138:307-316.

Flexas, J., A. Díaz-Espejo, J.A. Berry, J. Cifre, J. Galmés, R. Kaldenhoff, H. Medrano, and M. Ribas-Carbó. 2007. Analysis of leakage in IRGA's leaf chambers of open gas exchange systems: Quantification and its effects in 
photosynthesis parameterization. J. Expt. Bot. 58:1533-1543.

Flint, S.D. and M.M. Caldwell. 2003. A biological spectral weighting function for ozone depletion research with higher plants. Physiol. Plant. 117:137-144.

Gitelson, A.A., M.N. Merzlyak, and O.B. Chivkunova. 2001. Optical properties and nondestructive estimation of anthocyanin content in plant leaves. Photochem. Photobiol. 74(1):38-45.

Greenberg, B.M., V. Gaba, O. Canaani, S. Malkin, A.K. Mattoo, and M. Edelman. 1989. Separate photosensitizers mediate degradation of the 32$\mathrm{kDa}$ photosystem II reaction center protein in the visible and UV spectral regions. Proc. Natl. Acad. Sci. USA 86:6617-6620.

Hernández, R. and C. Kubota. 2016. Physiological responses of cucumber seedlings under different blue and red photon flux ratios using LEDs. Environ. Expt. Bot. 121:66-74.

Huché-Thélier, L., L. Crespel, J. Le Gourrierec, P. Morel, S. Sakr, and N. Leduc. 2016. Light signaling and plant responses to blue and UV radiations: Perspectives for applications in horticulture. Environ. Expt. Bot. 121:22-38.

Kataria, S. and K.N. Guruprasad. 2012. Intraspecific variations in growth, yield and photosynthesis of sorghum varieties to ambient UV (280-400nm) radiation. Plant Sci. 196:85-92.

Keller, M.M., Y. Jaillais, U.V. Pedmale, J.E. Moreno, J. Chory, and C.L. Ballare. 2011. Cryptochrome 1 and phytochrome B control shade-avoidance responses in Arabidopsis via partially independent hormonal cascades. Plant J. 67:195-207.

Kozuka, T., G. Horiguchi, G.T. Kim, M. Ohgishi, T. Sakai, and H. Tsukaya. 2005. The different growth responses of the Arabidopsis thaliana leaf blade and the petiole during shade avoidance are regulated by photoreceptors and sugar. Plant Cell Physiol. 46(1):213-223.

Kreslavski, V.D., V.Y. Lyubimov, G.N. Shirshikova, A.N. Shmarev, A.A. Kosobryukhov, F.-J. Schmitt, T. Friedrich, and S.I. Allakhverdiev. 2013. Preillumination of lettuce seedlings with red light enhances the resistance of photosynthetic apparatus to UV-A. J. Photochem. Photobiol. Bol. Biol. 122:1-6.

Krizek, D.T., S.J. Britz, and R.M. Mirecki. 1998. Inhibitory effects of ambient levels of solar UV-A and UV-B radiation of growth of cV. New Red Fire lettuce. Physiol. Plant. 103:1-7.

Krizek, D.T., R.M. Mirecki, and S.J. Britz. 1997. Inhibitory effects of ambient levels of solar
UV-A and UV-B radiation of growth of cucumber. Physiol. Plant. 100:886-893.

Liu, H., B. Hu, L. Zhang, X.J. Zhao, K.Z. Shang, Y.S. Wang, and J. Wang. 2017. Ultraviolet radiation over China: Spatial distribution and trends. Renew. Sustain. Energy Rev. 76:13711383.

Liu, Q., X. Yao, C. Zhao, and X. Cheng. 2011. Effects of enhanced UV-B radiation on growth and photosynthetic responses of four species of seedlings in subalpine forests of the eastern Tibet plateau. Environ. Expt. Bot. 74:151-156.

Mantha, S.V., G.A. Johnson, and T.A. Day. 2001. Evidence from action and fluorescence spectra that UV-induced violet-blue-green fluorescence enhances leaf photosynthesis. Photochem. Photobiol. 73(3):249-256.

Mariz-Ponte, N., R.J. Mendes, S. Sario, J.M.P. Ferreira de Oliveira, P. Melo, and C. Santos. 2018. Tomato plants use non-enzymatic antioxidant pathways to cope with moderate UVA/B irradiation: A contribution to the use of UV-A/B in horticulture. J. Plant Physiol. 221:32-42.

Merzlyak, M.N., O.B. Chivkunova, A.E Solovchenko, and K.R. Naqvi. 2008. Light absorption by anthocyanins in juvenile, stressed, and senescing leaves. J. Expt. Bot. 59(14):3903-3911.

Mishra, S. and J.P. Khurana. 2017. Emerging roles and new paradigms in signaling mechanisms of plant cryptochromes. Crit. Rev. Plant Sci. 36(2):89-115.

Moan, J. 2002. Visible light and UV radiation, p. 69-85. In: D. Brune, R. Hellborg, B.R.R. Persson, and R. Pääkkönen (eds.). Radiation at home, outdoors and in the workplace. Scandinavian Science Publisher, Oslo, Norway.

Nayak, L., B. Biswal, N.K. Ramaswamy, R.K. Iyer, J.S. Nair, and U.C. Biswal. 2003. Ultraviolet-A induced changes in photosystem II of thylakoids: Effects of senescence and high growth temperature. J. Photochem. Photobiol. Bol. Biol. 70(2):59-65.

Neugart, S. and M. Schreiner. 2018. UVB and UVA as eustressors in horticultural and agricultural crops. Scientia Hort. 234:370-381.

Rechner, O., S. Neugart, M. Schreiner, S. Wu, and H. Poehling. 2017. Can narrow-bandwidth light from UV-A to green alter secondary plant metabolism and increase Brassica plant defenses against aphids? PLoS One 12(11): e0188522.

Sarlikioti, V., P.H.B. de Visser, G.H. Buck-Sorlin, and L.F.M. Marcelis. 2011. How plant architecture affects light absorption and photosynthesis in tomato: Towards an ideotype for plant architecture using a functional-structural plant model. Ann. Bot. 108(6):1065-1073.

Sharkey, T.D., C.J. Bernacchi, G.D. Farquhar, and E.L. Singsaas. 2007. Fitting photosynthetic carbon dioxide response curves for $\mathrm{C}_{3}$ leaves. Plant Cell Environ. 30:1035-1040.

Taiz, L. and E. Zeiger. 2006. Plant physiology. 4th ed. Sinauer Associates, Sunderland, MA.

Tezuka, T., T. Hotta, and I. Watanabe. 1993. Growth promotion of tomato and radish plants by solar UV radiation reaching the Earth's surface. J. Photochem. Photobiol. Bol. Biol. 19:61-66.

Thornley, J.H.M. 1976. Mathematical models in plant physiology. Academic Press, London, UK.

Trouwborst, G., S.W. Hogewoning, O. van Kooten, J. Harbinson, and W. van Ieperen. 2016. Plasticity of photosynthesis after the "red light syndrome" in cucumber. Environ. Expt. Bot. 121:75-82.

Tsormpatsidis, E., R.G.C. Henbest, F.J. Davis, N.H. Battey, P. Hadley, and A. Wagstaffe. 2008. UV irradiance as a major influence on growth, development and secondary products of commercial importance in Lollo Rosso lettuce "Revolution" grown under polyethylene films. Environ. Expt. Bot. 63:232-239.

Verdaguer, D., M.A.K. Jansen, L. Llorens, L.O. Morales, and S. Neugart. 2017. UV-A radiation effects on higher plants : Exploring the known unknown. Plant Sci. 255:72-81.

Wargent, J.J., J.P. Moore, A.R. Ennos, and N.D. Paul. 2009. Ultraviolet radiation as a limiting factor in leaf expansion and development. Photochem. Photobiol. 85:279-286.

Wellburn, A.R. 1994. The spectral determination of chlorophylls $a$ and $b$, as well as total carotenoids, using various solvents with spectrophotometers of different resolution. J. Plant Physiol. 144:307-313.

Zhang, L., L.H. Allen, Jr., M.M. Vaughan, B.A. Hauser, and K.J. Boote. 2014. Solar ultraviolet radiation exclusion increases soybean internode lengths and plant height. Agr. For. Meteorol. 184:170-178.

Zhang, Y., E. Kaiser, Y. Zhang, Q. Yang, and T. Li. 2018. Short-term salt stress strongly affects dynamic photosynthesis, but not steady-state photosynthesis, in tomato (Solanum lycopersicum). Environ. Expt. Bot. 149:109-119. 